\title{
Drosophila Jun relays the Jun amino-terminal kinase signal transduction pathway to the Decapentaplegic signal transduction pathway in regulating epithelial cell sheet movement
}

\author{
X. Steven Hou, ${ }^{1}$ Elliott S. Goldstein, ${ }^{2}$ and Norbert Perrimon ${ }^{1,3}$ \\ ${ }^{1}$ Howard Hughes Medical Institute, Department of Genetics, Harvard Medical School, Boston, Massachusetts 02115 USA; \\ ${ }^{2}$ Department of Zoology, Arizona State University, Tempe, Arizona 85287 USA
}

\begin{abstract}
We have characterized mutations in the Drosophila homolog of the mammalian proto-oncogene c-Jun gene (Diun). We demonstrate that DJUN in the embryo is a downstream target of the JNK signal transduction pathway during dorsal closure formation, and that the function of the JNK/DJUN pathway is to control the localized expression of decapentalegic (dpp), a member of the TGF- $\beta$ growth factor family. In contrast to previous observations, we find that both in the embryo and during photoreceptor cell determination, DJUN is not regulated by a pathway that involves MAPK.
\end{abstract}

[Key Words: Jun; Drosophila Jun; JNK; Dpp; signal relay; dorsal closure]

Received March 27, 1997; revised version accepted May 7, 1997.

Investigations in mammalian cell systems have strongly suggested that the c-jun as well as c-fos genes have important roles in programs of cell growth and differentiation in which cells integrate external physiological signals to bring about appropriate transcriptional changes (Greenberg and Ziff 1984; Lee et al. 1987; Bartel et al. 1989; Ryder et al. 1989).

In Drosophila, only one jun- and one fos-related gene have been identified. Drosophila Jun and Fos exhibit biochemical similarity to their mammalian counterparts (Perkins et al. 1990; Zhang et al. 1990). Two different mitogen associated protein (MAP)-type kinases (MAPK), encoded by the basket (bsk) and rolled (rl) genes, are good candidates for kinases that phosphorylate and activate DJUN (Peverali et al. 1996; Riesgo-Escovar et al. 1996; Sluss et al. 1996). bsk encodes a homolog of mammalian Jun amino (N)-terminal kinase (JNK) (DJNK) (Riesgo-Escovar et al. 1996; Sluss et al. 1996). DJNK can efficiently phosphorylate DJUN in vitro, but it is not clear whether this occurs in vivo (Sluss et al. 1996). Furthermore, DJUN is phosphorylated directly by Rolled (Rl)/MAPK in vitro and this phosphorylation is enhanced in vivo when the gain-of-function Rl/MAPK Seven maker

${ }^{3}$ Corresponding author.

E-MAIL perrimon@rascal.med.harvard.edu; FAX (617) 432-7688. $\left(r l^{\mathrm{Sem}}\right)$ mutation is used (Peverali et al. 1996). Previous studies, using dominant negative and constitutively activated forms of Diun, have suggested that DJUN is a target of $\mathrm{Rl} / \mathrm{MAPK}$ in Sevenless (Sev) receptor tyrosine kinase (RTK) pathway for differentiation of R7 photoreceptor cells (Bohmann et al. 1994; Treier et al. 1995; Peverali et al. 1996). To gain insights into the function of DJUN and to identify the signal transduction pathways that regulate the activity of DJUN in vivo, we have isolated mutations in Diun and analyzed their mutant phenotypes. Our analysis implicates that DJUN is required for a cell sheet movement during dorsal closure in a Drosophila embryo.

In a wild-type embryo, dorsal closure begins during mid-embryogenesis, takes $\sim 2$ hr $(11-13$ hr after egg laying: stage 13-15) (Campos-Ortega and Hartenstein 1985; Martinez Arias 1993), and involves cell shape change but no cell divisions. Before stage 13 , all cells that comprise the ventral and lateral epidermis are polygonal in shape and become elongated after stage 15 (Young et al. 1993). Cell shape elongation along the dorsal-ventral axis starts from the dorsal-most cells of the epithelium and is driven by a structure at the dorsal side of the cells referred to as "the leading edge" during germ-band retraction. As dorsal closure proceeds, cell shape elongation is propagated to lateral and ventral epidermal cells. Dorsal closure is completed with the fusion at the dorsal mid- 
line of both edges and the internalization of the amnioserosa (Campos-Ortega and Hartenstein 1985; Martinez Arias 1993; Young et al. 1993).

A number of mutations in Drosophila have been identified that disrupt dorsal closure and display a common "dorsal open" phenotype (Jürgens et al. 1984; NüssleinVolhard et al. 1984; Wieschaus et al. 1984; Perrimon et al. 1989). Some of the corresponding genes have been analyzed at the molecular level. These genes can be assigned to two main classes: genes coding for structure proteins required for dorsal closure, and genes involved in the regulation of dorsal closure.

The first class includes zipper (zip), which encodes a nonmuscle myosin heavy chain (Young et al. 1993); inflated, coding for an $\alpha$-integrin subunit (Wilcox et al. 1989); lethal(1)myospheroid, coding for a $\beta$-integrin subunit (Mackrell et al. 1988); and coracle, which encodes a band 4.1 homolog (Fehon et al. 1994).

The second class of genes are most likely involved in triggering the dorsal closure process. These include members of the JNK and Decapentalegic (Dpp) signaling pathways. The JNK pathway is represented by $b s k$ (DJNK; Riesgo-Escovar et al. 1996; Sluss et al. 1996), hemipterous (hep), which encodes the Drosophila INK kinase (DINKK; Glise et al. 1995), and Drac, which is a homolog of mammalian small GTPase Rac (Luo et al. 1994; Harden et al. 1995). Mutations in bsk and hep and expression of a dominant-negative form of Drac $\left(\right.$ rac $\left.^{D N}\right)$ disrupt dorsal closure (Luo et al. 1994; Glise et al. 1995; Harden et al. 1995; Riesgo-Escovar et al. 1996; Sluss et al. 1996). The Dpp pathway is represented by the genes coding for Dpp receptors, thick veins and punt, as well as a downstream component encoded by the schnurri gene. Mutations in these genes also show dorsal open phenotypes (Affolter et al. 1994; Brummel et al. 1994; Nellen et al. 1994; Penton et al. 1994; Arora et al. 1995; Grieder et al. 1995; Letsou et al. 1995; Ruberte et al. 1995; Staehlong-Hampton et al. 1995).

We find that DJUN in vivo is a target of the JNK signal transduction pathway. Furthermore, we demonstrate that one of the functions of the JNK/DJUN pathways is to regulate the expression of $d p p$ in the dorsal-most cells of the embryonic epidermis during dorsal closure. Finally, in contrast to previous observations (Bohmann et al. 1994; Treier et al. 1995; Peverali et al. 1996), we find that both in the embryo and during photoreceptor cell determination, DJUN is not regulated by a pathway that involves MAPK.

\section{Results}

\section{Isolation of mutations in the Djun locus}

Diun maps to $46 \mathrm{E}$ on the right arm of chromosome 2, a region saturated previously for lethal complementation groups by Bour et al. (1995). Southern blots of genomic DNA from the lines associated with lethality revealed that one of the zygotic lethal mutations, which we named Diun ${ }^{1}$, identifies a deficiency of $-700 \mathrm{bp}$ in the 2.4-kb EcoRI fragment of Diun genomic DNA (Fig. 1B).
A

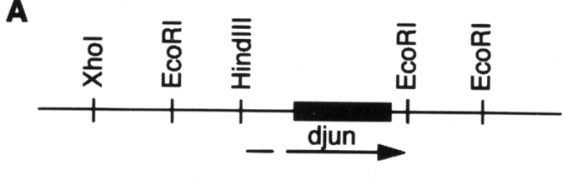

B

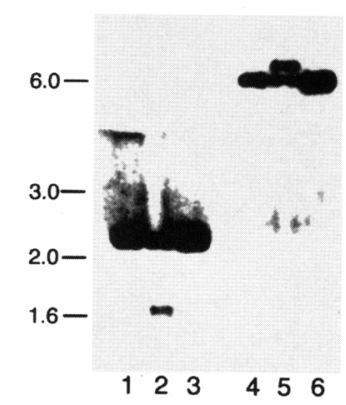

C

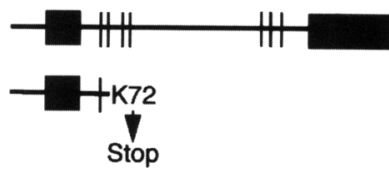

Figure 1. Molecular characterization of the Diun mutations. (A) Restriction map of the Diun gene (Wang and Goldstein 1994). (B) Southern hybridization analyses of Diun mutations. Genomic DNA was digested with restriction endonuclease EcoRI (lanes 1,2,3) and HindIII (lanes 4,5,6) and probed with Diun cDNA. DNA was prepared from flies of the following phenotypes. (Lanes 1,4) Wild type; (lanes 2,5) Djun $1 /+$; (lanes $3,6)$ Diun $^{2} /+$. The position of DNA size markers in kilobases is indicated. $(C)$ Schematic representation of wild-type and Diun ${ }^{2}$ gene products. The Delta domain (square), the bZIP DNA-binding domain (rectangle), and phosphorylation sites (vertical bars), are shown (Hill and Treisman 1995). The amino acid exchange found in Diun ${ }^{2}$ is indicated.

We found that Diun ${ }^{1}$ failed to complement a mutation identified previously 1(2)IA109, described by NüssleinVolhard et al. (1984), which we have renamed Diun ${ }^{2}$. The following additional lines of evidence demonstrate that the two mutations are in the Diun gene. First, a P-element transformed line that includes a $5-\mathrm{kb}$ Diun genomic DNA rescues the lethality of Diun ${ }^{1}$ and Diun ${ }^{2}$. Second, transient zygotic expression of a single copy of Diun cDNA under the heat shock promoter in Diun ${ }^{1}$ homozygous mutant embryos is sufficient to restore the mutant embryos to a wild-type phenotype /data not shown). Third, repeated heat shock induction of a hsDiun cDNA transgene during development was sufficient to rescue the lethality of transheterozygous Diun ${ }^{1} /$ Diun $^{2}$ animals. Finally, Diun ${ }^{2}$ appears normal on Southern blots (Fig. 1B), but sequence analysis revealed that Diun $^{2}$ sequence has a stop codon at amino acid position 72 , resulting in a predicted protein that terminates immediately after the amino-terminal "Delta" domain of the DJUN protein (Fig. 1C). Both Diun ${ }^{1}$ and Diun ${ }^{2}$ are likely to represent complete loss-of-function mutations in the Diun gene, as the embryonic phenotypes caused by Diun ${ }^{1}$ and Diun ${ }^{2}$ alleles when heterozygous to a de- 


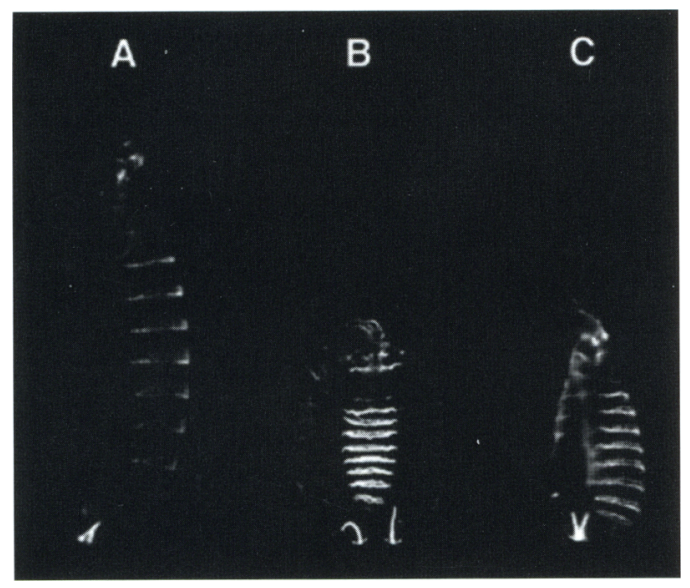

Figure 2. Cuticle phenotype of Diun embryos. (A) Dark-field cuticle pattern of a wild-type embryo. (B) Diun ${ }^{1} /$ Djun $^{1}$ embryo. (C) Diun ${ }^{2} /$ Diun $^{2}$ embryo. The embryos in $B$ and $C$ show similar dorsal open phenotypes represented by lack of thoracic and abdominal dorsal cuticle. $A$ and $C$ are lateral view. $B$ is a ventral view.

letion are the same as those caused by the corresponding Diun homozygotes.

\section{Djun mutations disrupt the initiation of dorsal closure}

Diun mutant animals derived from heterozygous mothers die during embryogenesis. They display head defects and lack the dorsal epidermis that is detected by a large dorsal hole in cuticle preparations (Fig. 2B,C).

We examined the dorsal closure process of Diun mutant embryos by staining with an anti-Engrailed (anti-En) antibody, which marks the border between the amnioserosa and the epidermis, and an anti-Spectrin antibody that stains the profiles of epidermal cells. In wild-type stage-14 embryos, the dorsal-most cells and most lateral epidermal cells have already elongated (Fig. 3A1), however, in Diun mutant embryos they remain polygonally shaped (Fig. 3A2) and dorsal closure never initiates. These defects can also be detected in embryos stained with anti-En (Fig. 3B). These results suggest that Diun is required for the initiation of dorsal closure.

The dorsal open phenotype may be attributable to incorrect patterning of the embryo at early stages, with dorsal epidermis defects appearing secondarily. To examine this possibility, we have used the expression pattern of Krüppel $(\mathrm{Kr})$ as a marker for proper amnioserosa differentiation (Ray et al. 1991). We found that $\mathrm{Kr}$ is expressed in Diun mutant embryos in patterns indistinguishable from those observed in wild-type embryos (data not shown). The apparently normal development of Diun embryos up to stage 13 was also revealed by the normal expression of the segment polarity gene en (data not shown; Fig. 3B2). In conclusion, Diun is not required for embryonic segmentation.
Diun regulates the DPP signal transduction pathway in the dorsal-most cells

The absence of dorsal closure is the major defect associated with Diun mutant embryos. Because several members of the Dpp signal transduction pathway also exhibit this phenotype (Brummel et al. 1994; Nellen et al. 1994; Penton et al. 1994; Arora et al. 1995; Grieder et al. 1995; Letsou et al. 1995; Ruberte et al. 1995; Staehlong-Hampton et al. 1995), we tested whether $d p p$ expression was affected in Diun mutant embryos. In wild-type embryos, $d p p$ is expressed in a complex pattern that includes expression in the dorsal-most cells of the epidermis during germ-band retraction (St. Johnston and Gelbart 1987; Jackson and Hoffmann 1994; see Fig. 4A1,B1). We found that $d p p$ transcripts are distributed normally in Diun mutants until the end of germ-band extension (data not shown). However, following the initiation of germ-band retraction, $d p p$ expression at the dorsal-most cells is dramatically disrupted, whereas expression in the visceral

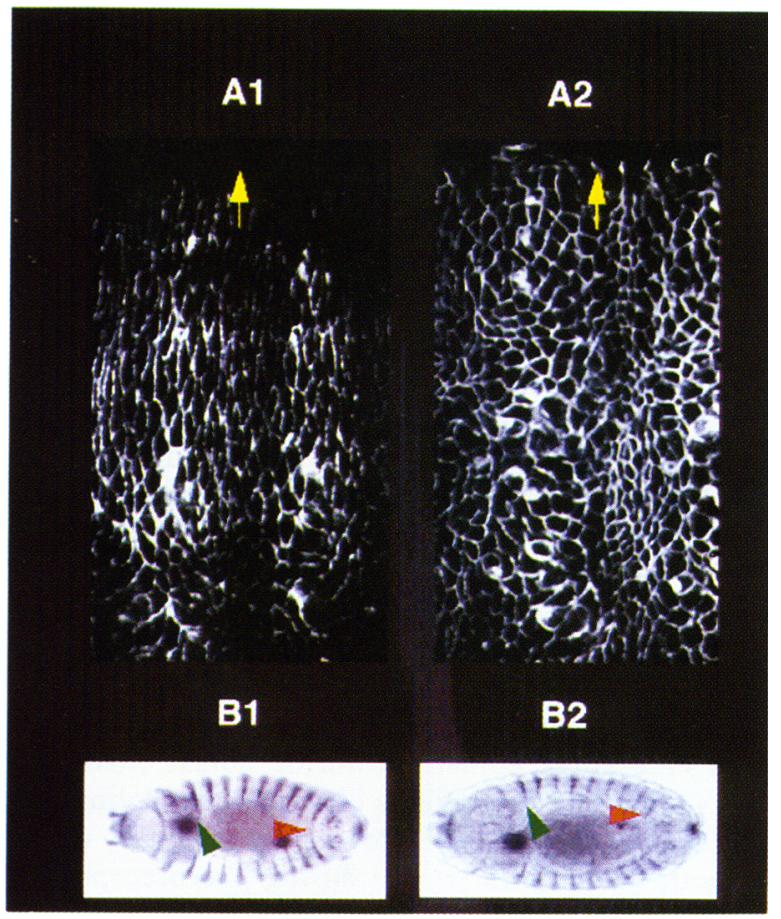

Figure 3. Diun mutation disrupts the initiation of dorsal closure. Epithelial cell shape changes during dorsal closure are revealed in wild-type $(A 1, B 1)$ and Diun mutant $\{A 2, B 2\}$ embryos. The cell profiles are illustrated with anti $\alpha$-Spectrin antibodies $(A 1, A 2)$. The border between amnioserosa and epidermis is marked with anti-En antibodies $(B 1, B 2)$. In wild-type stage-14 embryos, epidermal cells in both the dorsal-most (arrow) and lateral positions have elongated $(A 1)$, but the dorsal-most cells (indicated by arrow) in Diun mutant embryo remains polygonal shape (A2). Whereas the anterior- and posterior-most En stripes moved dorsal-ward and joined together (see arrowheads in $B 1, B 2)$ in wild-type stage-14 embryo $(B 1)$, they remain motionless in Diun mutant embryo (B2). Anterior is left. $A 1$ and $A 2$ are lateral views. $B 1$ and $B 2$ are dorsal views. 

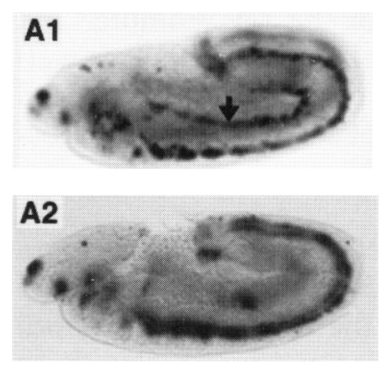
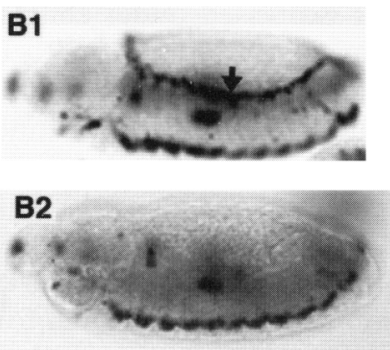

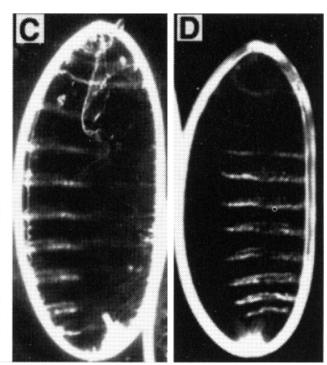

Figure 4. Diun regulates Dpp signal in the dorsal-most cells. $d p p$ in situ hybridizations $(A 1, A 2, B 1, B 2)$ to wild-type $(A 1, B 1)$ or Diun mutant $(A 2, B 2)$ embryos are shown. $d p p$ expression is normal in Diun mutant embryos up to full germ-band extension (data not shown). During $(A 2$, cf. with $A 1)$ and following $(B 2$, cf. with $B 1)$ germ-band retraction, the $d p p$ stripe of expression in the dorsalmost cells (arrows in $A 1$ and $B 1$ ) is dramatically disrupted. $(C, D)$ Ectopic expression of a constitutively active form of type I Dpp receptor TKV in the dorsal-most cells (see Materials and Methods for details) significantly rescues the dorsal open phenotype of homozygous Diun ${ }^{1}$ embryos. Most embryos are rescued fully and develop normally as indicated by the completely retracted germ band and well-developed head structures $(C)$. A small fraction of the embryos $(-20 \%)$ display head defects $(D)$ and variable dorsal defects probably reflecting variability in the level of expression of the activated TKV receptor.

mesoderm and the lateral ectoderm is normal (Fig. 4, cf. $\mathrm{A} 2$ with $\mathrm{A} 1$ and $\mathrm{B} 2$ with $\mathrm{B} 1$ ). These data suggest that DJUN specifically regulates, directly or indirectly, $d p p$ expression at the dorsal-most cells of the epidermis.

To determine whether the Dpp signal transduction pathway acts downstream of DIUN in regulating dorsal closure, we expressed a constitutively form of the type I Dpp receptor TKV $\left(\mathrm{TKV}^{\star}\right)$ (Hoodless et al. 1996) in the dorsal-most cells of a Diun mutant embryo using the targeted ectopic expression system (Brand and Perrimon 1993). Two transgenes were introduced separately into a Diun $^{1}$ mutant background. One of them contains a cDNA-encoding $\mathrm{TKV}^{\star}$ cloned downstream of Gal-4binding sites (Hoodless et al. 1996) and the other one expresses Gal4 under the control of the pannier (pnr) promoter (Calleja et al. 1996). Expression of TKV ${ }^{\star}$ rescues the dorsal open phenotype of Diun mutant embryos (Figs. $4 \mathrm{C}, \mathrm{D}$ ), consistent with the model showing that the function of DJUN during dorsal closure is to activate $d p p$ expression in the dorsal-most cells of the embryonic epidermis.

\section{Diun regulates the organization of the leading edge}

Cell shape elongation along the dorsal-ventral axis is driven by the leading edge in the dorsal-most cells during germ-band retraction. The leading edge is similar to mammalian focal adhesion plaques. It is enriched with tyrosine-phosphorylated proteins, most notably paxillin, and also corresponds to the actin and myosin nucleation sites (Harden et al. 1996; Fig. 5). The movement of a molecular motor myosin with a filamentous actin substrate is believed to be driving cell shape changes (Young et al. 1993). We compared the distribution of phosphotyrosine, actin, and myosin in wild-type (Figs. $5 \mathrm{~A} 1, \mathrm{~B} 1, \mathrm{C} 1$ ) and Diun mutant embryos (Figs. 5A2,B2,C2). Although phosphotyrosine, actin, and myosin are gradually accumulated at the leading edge following dorsal closure progression (Fig. 5Al,Bl,Cl), this localization is disrupted totally in Diun mutant embryos (Fig. $5 \mathrm{~A} 2, \mathrm{~B} 2, \mathrm{C} 2)$. These data suggest that DJUN regulates the initiation of dorsal closure through regulating the organization of the leading edge.
In the embryo, Djun acts downstream of the INK cascade but not downstream of RI/MAPK

Previous studies indicated that Diun is expressed maternally (Perkins et al. 1990; Zhang et al. 1990). To determine whether Diun is involved in earlier embryonic processes that may have been masked by the maternally derived product, we examined the effect of removal of the maternal contribution by examining the phenotype of embryos derived from females carrying homozygous Diun germ-line clones. Embryos lacking both maternal and zygotic Diun activity have similar phenotypes to those of homozygous mutant embryos (data not shown), indicating that removing maternal Diun activity has no or little effect on embryonic development. In particular, these embryos have no terminal defects, indicating that DJUN is not involved in the Torso RTK signaling pathway (Duffy and Perrimon 1994). In addition, these embryos, unlike zygotic DER (Drosophila EGF receptor) null mutant embryos (Ray and Schupbach 1996), differentiate cuticle with denticle belts and their segmenta-
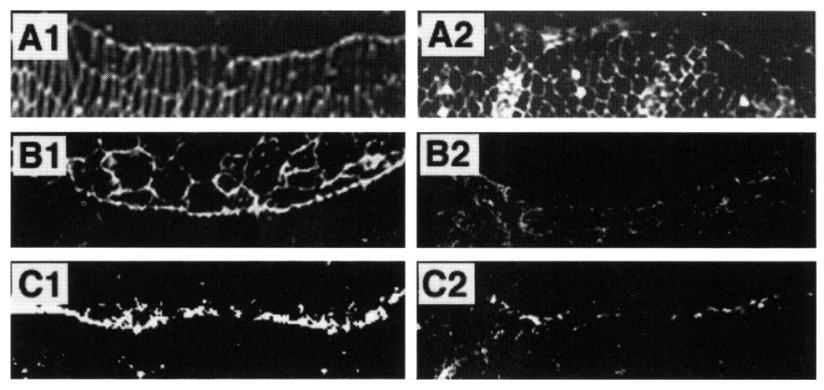

Figure 5. Diun controls the organization of the leading edge. The distribution of phosphotyrosine $(A 1, A 2)$, filamentous actin $(B 1, B 2)$, and nonmuscle myosin heavy chain $(C 1, C 2)$ are shown in wild-type embryos $\{A 1, B 1, C 1\}$ and Diun mutant embryos $(A 2, B 2, C 2)$. Embryos were stained for filamentous actin with phalloidin or for phosphotyrosine and nonmuscle myosin heavy chain with antibodies. Whereas phosphotyrosine $(A 1)$, actin (B1), and myosin (C1) are accumulated along the leading edge in wild-type embryos, these accumulations are disrupted completely in Diun mutant embryos $(A 2, B 2, C 2)$. Anterior is to the left. All panels are lateral views. 
tion appears normal (Fig. 2). These results suggest that Diun is not involved in RTK-RAS1-DRAF-Rl/MAPK signal transduction pathways during embryogenesis.

To test whether, and where, DJUN acts in the JNK signal pathway, we introduced constitutively activated Diun under control of the heat shock gene promoter and enhancer (hs-Diun ${ }^{A s p}$ ) (Treier et al. 1995) into $D R a c^{D N}$, hep, and bsk embryos (see introductory section). In addition, we also introduced $h s-D_{i u n}{ }^{A s p}$ into Dsor 1 (Drosophila Rl/MAPK) mutant embryos to determine whether activated Jun can rescue the defects associated with loss of RTK activities in the embryo. The heat shock treatment significantly rescued the dorsal open phenotype of $D r a c^{D N}$, hep, and bsk embryos (Fig. 6) but had no effect on the Dsor 1 maternal effect phenotype.

In summary, Diun mutations exhibit dorsal closure defects that are also found in embryos missing Drac, hep, or bsk gene activities. They do not have any of the phenotypes expected if DJUN was a component of RTK pathways such as the Torso or DER signaling pathways. Furthermore, constitutively activated Diun rescues the mutant phenotype of components in the JNK pathway but not the mutant phenotype of a component in the $\mathrm{R} 1 /$ MAPK pathway. These results suggest that DJUN is a specific target of INK during embryogenesis but not of $\mathrm{Rl} / \mathrm{MAPK}$.

Djun is not a target of Rl/MAPK in Sev signal transduction pathway for photoreceptor cell fate specification in the eye

To characterize the function of Diun in Sev signaling, we examined the effects of Diun mutations on signaling by activated Sev $\left(\operatorname{sev}^{S 11}\right)$ and activated Draf $\left(\right.$ raf $\left.{ }^{\text {torY9 }}\right)$ pro- teins expressed under control of the $\mathrm{sev}$ promoter and enhancer (Basler et al. 1991; Dickson et al. 1992) as well as its effect on an activated R1/MAPK protein provided by the $r l^{\mathrm{Sem}}$ mutation (Brunner et al. 1994). Heterozygosity of Diun did not suppress the rough eye phenotype (Fig. 7; data not shown).

We also generated clones of cells homozygous for Diun following mitotic recombination in the eye to directly examine the role of DJUN in the eye. Clones of Diun mutant cells were similar in size and number to those found in the control (Fig. 7). These results indicate that Diun, like bsk (Riesgo-Escovar et al. 1996) but not like mutants in Sev RTK signal transduction pathway, is not required for photoreceptor cell differentiation in the eye.

\section{Discussion}

We have identified mutations in the Drosophila homo$\log$ of the mammalian proto-oncogene c-jun gene (Diun). In contrast to previous observations (Bohmann et al. 1994; Treier et al. 1995; Peverali et al. 1996), we find that both in the embryo and during photoreceptor cell determination, DJUN is not regulated by a pathway that involves MAPK. In the embryo, DJUN is a target of a pathway that involves JNKK/JNK. Diun mutations disrupt the initiation of dorsal closure suggesting that the JNKK/ JNK/DJUN pathway is important for proper morphogenetic activity of cell sheets. One downstream target of DJUN is $d p p$. $d p p$ transcription in the dorsal-most cells is disrupted in Diun mutants. Our data suggest that DJUN connects JNK signal transduction pathway to Dpp signal transduction pathway in regulating dorsal closure.

Figure 6. Diun is epistatic to Drac, hep, and $b s k$, but not to Dsor1. The dark-field cuticle pattern is of embryos of the following genotypes. (A1) UAS-Drac ${ }^{N 17.1} / \mathrm{hs}-$ Gal-4; (A2) +/hs-Diun ${ }^{\text {Asp }}$; UAS-Drac ${ }^{\text {N17.1 }} /$ hs-Gal-4; (B1) hep $^{1}$; (B2) hep ${ }^{1}$ + +hs-Diun ${ }^{A s p} ;$ (C1) bsk ${ }^{1}$ / $b s k^{1}$; (C2) bsk ${ }^{1} h s-D i u n^{A s p} / b s k^{1} h s-D i u n^{A s p}$; (D1) Dsor $1^{L H 110}$ (derived from Dsor1 ${ }^{L H 110}$ / Dsor $1^{\text {LH11O }}$ germ-line clones; Lu et al. 1994); and (D2) Dsor $1^{\text {LH110 }}+/ /$ hs-Diun ${ }^{A s P}$. Embryos with one copy hs-Djun ${ }^{A s p}$ were heat-shocked for $30 \mathrm{~min}$ at 5-7 hr after egg laying. Embryos with two copies of $h s-D_{i u n}{ }^{A s p}$ are without heat shock treatment. Constitutively activated Diun significantly rescued the dorsal open phenotype of $\operatorname{Drac}^{N 17.1}(A 2)$, hep ${ }^{1}(B 2)$, and $b s k^{1}(C 2)$, but does not rescue the mutant phenotype of Dsor $1^{L H 11 O}(D 2)$. Embryos that lack both maternal and zygotic Dsor 1 function develop poorly differentiated cuticle that resemble the loss of DER signaling (Lu et al. 1994). This phenotype is not rescued by expression of activated Jun. In all panels anterior is left, and dorsal is up. hs-Djun ${ }^{A s p}$ is the constitutively activated form of Diun under

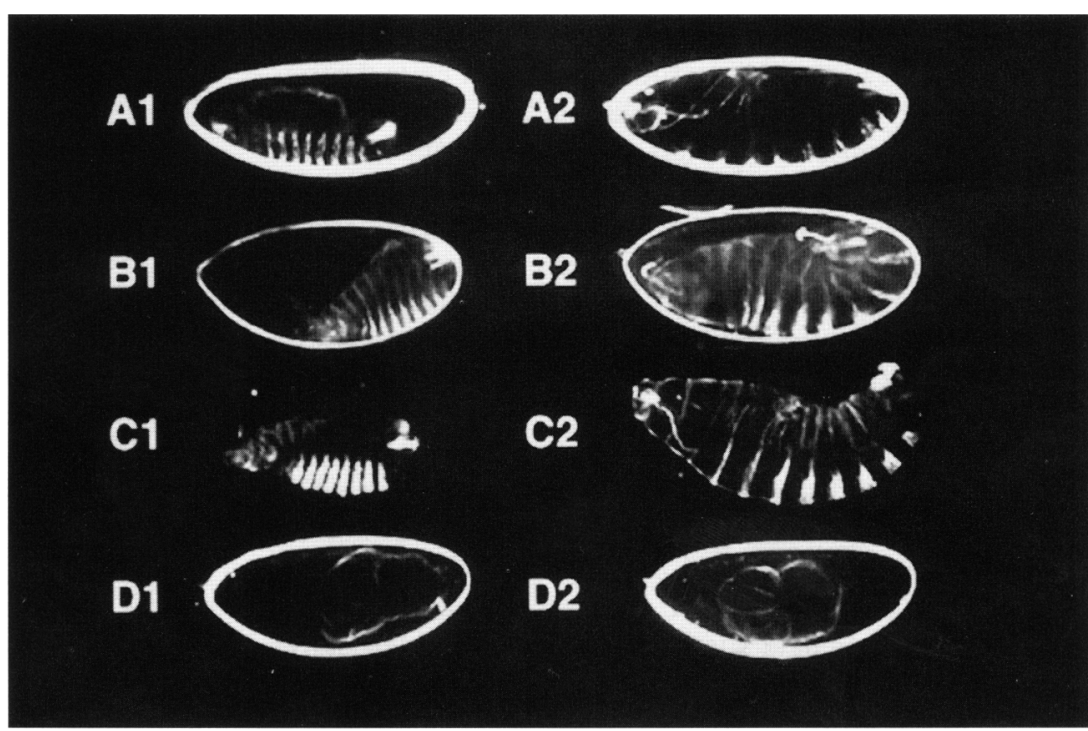
heat shock promoter. 


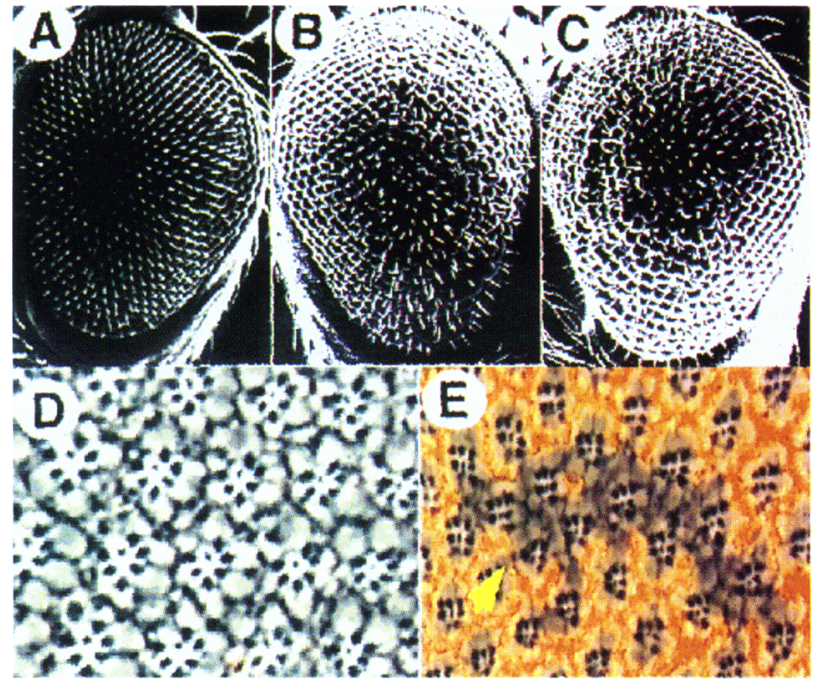

Figure 7. Diun is not required for Sev RTK signal transduction and specification of photoreceptor cell fates. $(A-C)$ Scanning electron micrographs (SEMs) of adult eyes of the following genotypes. (A) Wild-type (Oregon R); $(B)$ raf $^{\text {torY9 }} /+;(C)$ raf forY $^{\text {to }} /$ Diun $^{1}$. Note that the raf ${ }^{\text {torY9 }}$ rough eye phenotype is not suppressed by removal of one copy of Diun ${ }^{1}$ (cf. $C$ with B). Diun ${ }^{1}$ also does not suppress the rough eye phenotypes of $\mathrm{sev}^{\mathrm{si1}}$ and $r 1^{\mathrm{Sem}}$ (data not shown). $(E, F)$ Tangential sections of eyes of wild-type $(E)$ and Diun $^{1} /+$ flies carrying a clone (arrowhead) of homozygous Diun ${ }^{1}$ cells (marked by the absence of pigment granules). Note that all ommatidia in the mutant clone are wild type.

Diun functions in the INK pathway but not MAPK pathway in both the embryo and in the eye

Several lines of evidence suggest that DJUN functions in the JNKK/JNK pathway but not in RTK/MAPK signaling pathways in the embryo. First, embryos that lack both maternal and zygotic Diun activity have similar dorsal open phenotypes. The absence of additional phenotypes, such as terminal defects or poorly differentiated cuticle in germ-line clone-derived embryos, indicates that DJUN is not a component of either the Torso or DER/EGFR RTK signaling pathways. Second, the constitutively activated form of Diun rescues the mutant phenotypes of members of the JNK pathway but not of Dsor1, a member of the Rl/MAPK pathway. These observations place DJUN downstream of JNK but not of Rl/MAPK.

In addition, there are two lines of evidence against a function of DJUN in the Rl/MAPK pathway in the eye. First, homozygous Diun clones induced in the developing Drosophila eye imaginal disc do not affect photoreceptor differentiation. Second, reduction of Diun activity by half does not suppress ectopic photoreceptor cell differentiation triggered by constitutively activated forms of either the Sev, Raf, or Rl/MAPK. These genetic results on the function of Diun in the eye are consistent with the observation that $b s k / J N K$ also does not affect photoreceptor cells differentiation (Riesgo-Escovar et al. 1996).
Our conclusion is in contrast to the previous observations (Bohmann et al. 1994; Treier et al. 1995; Peverali et al. 1996), which reported that DJUN was a target of Rl/ MAPK in Sev signaling. A simple explanation is that the previous experiments were performed under nonphysiological conditions. The dominant negative and constitutively activated forms of DJUN employed in these experiments may bind to factors regulated by the MAPK pathway and block their normal functions, or the modified Jun proteins may compete with factors in the MAPK pathway for binding to the promoter elements of downstream target genes. Alternatively, there may be another jun gene in the Drosophila genome.

\section{Role of the INK/DIUN pathway during dorsal closure}

In embryos, DJUN is a target of a pathway that involves JNKK/JNK. Diun mutations disrupt the initiation of dorsal closure, suggesting that it is important for proper morphogenetic activity of cell sheets. DJUN may accomplish its function in this process by controlling Dpp signal transduction pathway in the leading edge. Therefore, this is a relay process of four members: JNK pathway to DJUN, DJUN to $d p p$, and Dpp pathway to the leading edge, which drives the cell shape change and cell movement. A model for the relay signal transduction pathway is presented in Figure 8.

The requirement of a Drac-Hep-Bsk-DJUN signal transduction pathway for dorsal closure during embryogenesis is supported by the following data. First, mutations in Diun (Fig. 2), bsk, hep, and expression of dominant-negative forms of Drac (Drac ${ }^{D N}$ ) (Luo et al. 1994; Glise et al. 1995; Harden et al. 1995; Riesgo-Escovar et al. 1996; Sluss et al. 1996) disrupt dorsal closure; second, activated DJUN rescues the dorsal open phenotype of $D_{a a c}{ }^{D N}$, hep, and bsk embryos; third, Hep phosphorylates and activates Bsk, and Bsk phosphorylates DJUN in vitro (Sluss et al. 1996); fourth, mammalian JNK is activated by Rac-family GTPases (Coso et al. 1995; Hill et al. 1995; Minden et al. 1995).

One downstream target of DJUN is $d p p$. $d p p$ transcription in the dorsal-most cells is disrupted by Diun mutations. Targeted expression of constitutively activated forms of the type I Dpp receptor TKV in the dorsal-most cells rescues the dorsal open phenotype of Diun mutations. Mutations in components of the Dpp signaling pathway exhibit dorsal open phenotypes (see introductory section), indicating that the Dpp signaling pathway is required for dorsal closure. These data suggest that the role of DJUN during this process is to relay the JNK pathway to the Dpp pathway through specifically regulating $d p p$ expression in the dorsal-most cells.

Members of the mammalian Jun, Fos family belong to the AP-1 transcription factor family. All members of this group share the same binding specificity for a palindromic DNA sequence, the AP-1-binding site, which functions as a signal-responsive transcription control element in a number of cellular and viral promoters (Angel et al. 1987; Bohmann et al. 1988). The DNA-binding competent and transcriptional active form of AP-1 is a 
Figure 8. Model of the role of DJUN in dorsal closure formation. See text.

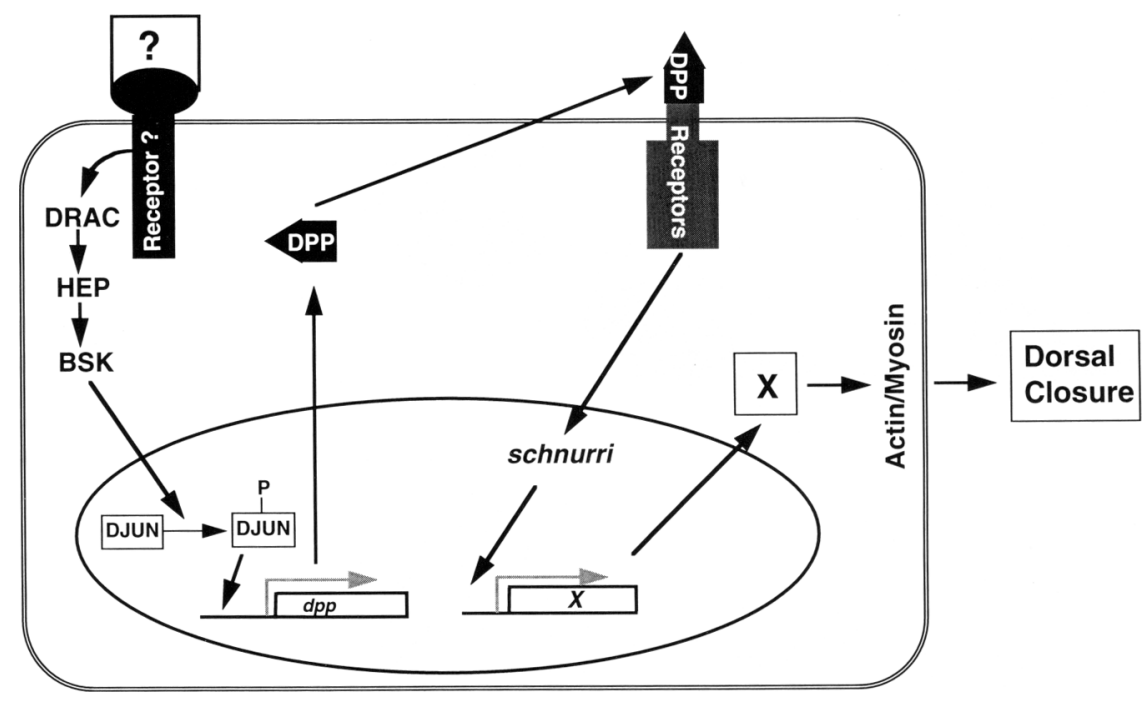

protein dimer formed by two family members through a coiled-coil interaction. Diun is expressed ubiquitously in embryos (Perkins et al. 1990; Zhang et al. 1990), it may cooperate with another locally expressed factor to turn on $d p p$ expression in the dorsal-most cells. It is possible that DFOS represents such a partner of DJUN in regulating $d p p$ as $D f o s$ is expressed in the dorsal ectoderm and amnioserosa at $8 \mathrm{hr}$ of embryogenesis (Perkins et al. 1990; Rusch and Levine 1997). However, it is equally likely that an unknown transcription factor interacts with DJUN in regulating $d p p$ expression in the dorsal-most cells.

\section{Dorsal closure formation: a model}

In Figure 8 we propose a model for the process of dorsal closure formation. DJUN regulates $d p p$ expression in the dorsal-most cells and Dpp signal is also transduced in these cells, this relay process may be carried out in the same cells. The JNK pathway first phosphorylates and activates DJUN, DIUN then regulates $d p p$ expression in the dorsal-most cells. Subsequently, the Dpp protein is secreted, binds to its receptors on the cell surface, and signals back to the nucleus to regulate gene $X$ expression, whose product organizes the leading edge to drive cell shape changes for dorsal closure. It should be noted that our experiments did not address whether DJUN acts directly on the $d p p$ promoter or not, such that it is possible that the effect of DJUN on $d p p$ expression is indirect.

The nature of the signal/receptor that activates the JNK/DJUN pathway in the dorsal epidermis remains to be characterized. Recent studies in mammalian cells have shown that the stress-activated protein kinases (SAPKs)/JNKs can be activated by inflammatory cytokines such as tumor necrosis factor $\alpha(\mathrm{TNF} \alpha)$ and IL-1, as well as G protein-coupled receptors (Coso et al. 1995; Davis 1995; Hill et al. 1995; Minden et al. 1995). The
Drosophila JNK/DJUN may be activated by similar signals.

\section{Concluding remarks}

An emerging concept of pattern formation is the relay of signal transduction pathways to pattern tissues. For examples, Dpp expression is regulated by the Hedgehog signaling pathway during anteroposterior patterning of the wing disc (Lawrence and Struhl 1996). Similarly, localized activation of the Notch signaling pathway defines the late domain of expression of Wingless during dorsoventral patterning of the wing disc (Kim et al. 1996). Here we have demonstrated another such example whereby the JNK/DIUN pathway regulates dorsal closure by regulating Dpp expression.

\section{Materials and methods}

Drosophila stocks

The screen for specific mutations in the $46 \mathrm{C}-\mathrm{F}$ regions was described in Bour et al. (1995). Diun ${ }^{1}$ is among these mutations and was originally named 76-19. 1(2)IA109 and $b s k^{1}$ were obtained from the Tübingen Stock Collection; hep ${ }^{1}$ from $S$. Noselli (University of Toulouse, France); UAS-TKV ${ }^{\star}$ [described as UAS-TKV(Q199D) in Hoodless et al. 1996] from $M$. $\mathrm{O}^{\prime}$ Connor (University of California, Irvine) via S. Newfeld (Harvard University, Boston, MA); and pnr-Gal-4 from the Bloomington Stock Center. Dsor $1^{\mathrm{LH11O}}$ is described in Lu et al. (1994). $\operatorname{Drac}^{N 17.1}$ transgenic flies were from L. Luo (University of California, San Franciscol and heat shock Diun cDNA transgenic flies from M. Mlodzik (European Molecular Biology Laboratory, Heidelberg, Germany). hs-Gal-4 was generated by A. Brand in this laboratory. To test for genetic interactions between Diun and components of the Sev pathway, the following stocks were obtained from E. Hafen (University of Zürich, Switzerland): sev $^{\text {S11.1 }}$ (Basler et al. 1991), sE-raftorY9 (Dickson et al. 1992), and $r^{\text {Sem }}$ (Brunner et al. 1994).

Flies were raised on standard Drosophila media at $25^{\circ} \mathrm{C}$, un- 
less indicated. Chromosomes and mutations that are not described in the text can be found in Lindsley and Zimm (1990).

\section{Genetic rescue}

A P-element rescue plasmid was constructed by inserting a 5.2kb XhoI-XbaI fragment containing Diun into the pw8 vector (E.S. Goldstein, unpubl.). The insert contained $2.2 \mathrm{~kb}$ upstream and $\sim 0.8 \mathrm{~kb}$ of downstream sequence. Germ-line transformants were produced by standard methods (Spradling and Rubin 1982) following injection of the rescue and a helper plasmid. Four independent X-chromosome lines were obtained and crossed in $D f(2 R) X 1 / C y O$, a deficiency that uncovers the $46 \mathrm{C}-\mathrm{F}$ region. These lines were then crossed to zygotic lethal mutations and scored for the presence of straight wing flies.

\section{Molecular biology techniques}

Genomic DNAs were isolated from adult flies, digested with restriction enzymes, and analyzed on Southern blots using Diun cDNA as a probe under standard conditions (Sambrook et al. 1989).

PCR primers 5'-GGAATTCCCTTCATCCGAATCAGATTGACG-3' and 5'-GGAATTCCTCATCATTCTCCCCGGCT-3' were used to amplify genomic DNA fragments from Diun ${ }^{2}$ homozygous mutant embryos, and the product was subcloned. DNAs from five separate clones were sequenced and all identified the same AAG to TAG mutation at amino acid 72 .

\section{Antibody staining and immunohistochemistry}

Antibody and phalloidin stainings and confocal microscopy of embryos were performed as described previously (Harden et al. 1995). Embryos aged $10-14 \mathrm{hr}$ at $25^{\circ} \mathrm{C}$ were used to study the process of dorsal closure. Anti- $\alpha$-Spectrin antibody (obtained from D. Branton, Harvard University, Boston, MA) were used at 1:1000 dilution, anti-nonmuscle myosin antibody (obtained from D. Kiehart, Duke University Medical School, Durham, $\mathrm{NC}$ ) at a 1:500, and anti-Engrailed antibody (obtained from R. Holmgren, Northwestern University, Evanston, IL) at 1:200.

In situ hybridization of whole-mount embryos using digoxigenin-labeled antisense of a $d p p$-coding DNA probe was performed as described (Hou et al. 1995).

\section{Genetic interactions}

To test for interactions between Diun and Drac ${ }^{D N}$, hep, bsk, and Dsor1, the following stocks were constructed: hep $p^{1} / F M 7$; hs-Diun ${ }^{A s p} /+$ and FM7/Y; hs-Diun ${ }^{A s p} /+$, bsk hs-Diun ${ }^{A s p} / C y o$, $h s-D_{i u n}^{A s p} /+; U A S-D_{12}{ }^{N 17.1} / U A S-D r a c^{N 17.1}$, and $h s-D i u n^{A s p} /+$; hs-Gal-4/hs-Gal-4. Embryos with genotypes hep ${ }^{1} / Y$; hsDiun $^{\text {Asp }} /+$, bsk hs-Djun ${ }^{\text {Asp }} /$ bsk hs-Diun Asp, hs-Diun ${ }^{A s p} /+$; $U A S-D r a c^{D N} / h s-G a l-4$ were collected for $2 \mathrm{hr}$ and aged to 5-7 $\mathrm{hr}$ after egg laying before a $30-60 \mathrm{~min}$ heat shock. Following heat shock, the embryos were aged for another $24 \mathrm{hr}$ at $25^{\circ} \mathrm{C}$ before cuticle preparation. The cuticle phenotypes were compared for embryos that are either with and/or without the constitutively activated Diun transgene.

Targeted ectopic expression of an activated form of type I DPP receptor $\mathrm{TKV}, \mathrm{TKV}^{\star}$, to the dorsal-most cells was achieved using the Gal-4/UAS system (Brand and Perrimon 1993). A UAS$\mathrm{TKV}^{\star}$ element on the third chromosome (Hoodless et al. 1996) was induced in Diun ${ }^{1}$ homozygous embryos. The inducer line was the pnr-Gal-4 line on the third chromosome (Calleja et al. 1996).

\section{Clonal analysis and histology}

Germ-line clones of Diun were generated using the "FLP-DFS" technique (Chou and Perrimon 1996).

For generating clones in adult eyes, the FLP-FRT recombinase system (Xu and Rubin 1993) was used. Second chromosomes carrying Diun mutations and $F R T^{42 D}$ were constructed. Virgin females of genotype $F R T^{42 D} W^{+} F L P$ were mated with males of genotype $W ; F R T^{42 D}$-Diun/CyO. Clones were induced in first instar larvae and examined in adult eyes.

Scanning electron microscopy and histological sections of eyes were done as described (Basler et al. 1991).

\section{Acknowledgments}

We thank S. Noselli, M. Mlodzik, L. Luo, E. Hafen, C. NüssleinVolhard, M. O'Connor, and T. Xu for Drosophila stocks; D. Branton, D. Kiehart, and R. Holmgren for antibodies; E. Noll for help with confocal microscopy, D. Eberl for eye section, $M$. Zeidler for help in analyzing the eye phenotypes, and E. Seling for scanning electron microscopy; N. Harden for immunostaining protocol; S. Treadway and A.E. Stephenson for complementation analysis and J. Lim for help with the germ-line constructs; M. Mlodzick and E. Hafen for communicating results before publication. This work is supported by a Leukemia Society of America postdoctoral fellowship to X.S.H, by grants from the Del E. Webb Foundation and National Institutes of Health (BRSG 2 s07 Ro7112) to E.S.G, and by the Howard Hughes Medical Institute from which N.P. is an investigator.

The publication costs of this article were defrayed in part by payment of page charges. This article must therefore be hereby marked "advertisement" in accordance with 18 USC section 1734 solely to indicate this fact.

\section{References}

Affolter, M., D. Nellen, U. Nussbaumer, and K. Basler. 1994. Multiple requirements for the receptor serine/threonine kinase thick veins reveal novel functions of TGF $\beta$ homologs during Drosophila embryogenesis. Development 120: 31053117.

Angel, P., M. Imagawa, R. Chiu, B. Stein, R.J. Imbra, H.J. Rahmsdorf, C. Jonat, C. Herrlich, and M. Karin. 1987. Phorbol ester-inducible genes contain a common cis element recognized by a TPA-modulated trans-acting factor. Cell 49: 729-739.

Arora, K., H. Dai, S.G. Kazuko, J. Jamal, M.B. O'Connor, A. Letsou, and R. Warrior. 1995. The Drosophila schnurri gene acts in the Dpp/TGF $\beta$ signaling pathway and encodes a transcription factor homologous to the human MBP family. Cell 81: 781-790.

Bartel, D., M. Sheng, L. Lau, and M.E. Greenberg. 1989. Growth factors and membrane depolarization activate distinct programs of early response gene expression: Dissociation of fos and jun induction. Genes \& Dev. 3: 304-313.

Basler, K., B. Christen, and E. Hafen. 1991. Ligand-independent activation of the sevenless receptor tyrosine kinase changes the fate of cells in the developing Drosophila eye. Cell 64: 1069-1081.

Bohmann, D., A. Admon, R. Turner, and R. Tjian. 1988. Transcriptional regulation by the AP-1 family of enhancer-binding proteins: A nuclear target for signal transduction. Cold Spring Harber Symp. Quant. Biol. 53: 695-700.

Bohmann, D., M.C. Ellis, L.M. Staszewski, and M. Mlodzik. 1994. Drosophila Jun mediates Ras-dependent photoreceptor 
determination. Cell 78: 973-986.

Bour, B.A., M.A. O'Brien, W.L. Lockwood, E.S. Goldstein, R. Bodmer, P.H. Taghert, S.M. Abmayr, and H.T. Nguyen. 1995. Drosophila MEF2, a transcription factor that is essential for myogenesis. Genes \& Dev. 9: 730-741.

Brand, A.H. and N. Perrimon. 1993. Targeted gene expression as a mean of altering cell fates and generating dominant phenotypes. Development 118: 401-415.

Brummel, T.J., V. Twombly, G. Marqués, J.L. Wrana, S.L. Newfeld, L. Attisano, J. Massagué, M.B. O'Connor, and W.M. Gelbert. 1994. Characterization and relationship of dpp receptors encoded by the saxophone and thick veins genes in Drosophila. Cell 78: 251-261.

Brunner, D., N. Oellers, J. Szabad, W.H. Biggs III, L.H. Zipursky, and E. Hafen. 1994. A gain-of-function mutation in Drosophila MAP kinase activates multiple receptor tyrosine kinase signaling pathways. Cell 76: 875-888.

Calleja, M., E. Moreno, S. Pelaz, and G. Morata. 1996. Visualization of gene expression in living adult Drosophila. Science 274: 252-255.

Campos-Ortega, J.A. and V. Hartenstein. 1985. In The embryonic development of Drosophila melanogaster. Springer-Verlag, Berlin, Germany.

Chou, T.B. and N. Perrimon. 1996. The autosomal FLP-DFS technique for generating germline mosaics in Drosophila melanogaster. Genetics 144: 1673-1679.

Coso, O.A., M. Chiariello, J.-C. Yu, H. Teramoto, P. Crespo, N. $\mathrm{Xu}, \mathrm{T}$. Miki, and J.S. Gutkind. 1995. The small GTP-binding proteins rac1 and cdc42 regulate the activity of the JNK/ SAPK signaling pathway. Cell 81: 1137-1146.

Davis, R. 1995. Transcriptional regulation by MAP kinases. Mol. Reprod. Dev. 42: 459-467.

Dickson, B., F. Sprenger, D. Morrison, and E. Hafen. 1992. Raf functions downstream of Rasl in the sevenless signal transduction pathway. Nature 360: 600-603.

Duffy, J.B. and N. Perrimon. 1994. The torso pathway in Drosophila: Lessons on receptor tyrosine kinase signaling and pattern formation. Dev. Biol. 166: 380-395.

Fehon, R.G., I.A. Dawson, and S. Artavanis-Tsakonas. 1994. A Drosophila homologue of membrane-skeleton protein 4.1 is associated with septate junctions and is encoded by the coracle gene. Development 120: 545-557.

Glise, B., H. Bourbon, and S. Noselli. 1995. hemipterous encodes a novel Drosophila MAP kinase kinase, required for epithelial cell sheet movement. Cell 83: 451-461.

Greenberg, M.E. and E.B. Ziff. 1984. Stimulation of 3T3 cells induces transcription of the fos proto-oncogene. Nature 311: 433-438.

Grieder, N.C., D. Nellen, R. Burke, K. Basler, and M. Affolter. 1995. schnurri is required for Drosophila Dpp signaling and encodes a zinc finger protein similar to the mammalian transcription factor PRDII-BF1. Cell 81: 791-800.

Harden, N., H.Y. Loh, W. Chia, and L. Lim. 1995. A dominant inhibitory version of the small GTP-binding protein Rac disrupts cytoskeletal structures and inhibits developmental cell shape change in Drosophila. Development 121: $903-914$.

Harden, N., J. Lee, H.Y. Loh, Y.M. Ong, I. Tan, T. Leung, E. Manser, and L. Lim. 1996. A Drosophila homolog of the Racand Cdc42-activated serine/threonine kinase PAK is a potential focal adhesion and focal complex protein the colocalizes with dynamic actin structures. Mol. Cell. Biol. 16: 1896-1908.

Hill, C.S. and R. Treisman. 1995. Transcriptional regulation by extracellular signals: Mechanisms and specificity. Cell 80: 199-211.
Hill, C.S., J. Wynne, and R. Treisman. 1995. The rho family GTPases rhoA, rac1, and $\mathrm{Cdc} 42 \mathrm{Hs}$ regulate transcriptional activation by SRF. Cell 81: 1159-1170.

Hoodless, P.A., T. Haerry, S. Abdollah, M. Stapleton, M.B. O'Connor, L. Attisano, and J.L. Wrana. 1996. MADR1, a MAD-related protein that functions in BMP2 signaling pathways. Cell 85: 489-500.

Hou, X.S., T.B. Chou, M.B. Melnick, and N. Perrimon. 1995. The Torso receptor tyrosine kinase can activate raf in a rasindependent pathway. Cell 81: 63-71.

Kim, J., A. Sebring, J. Esch, M.E. Kraus, K. Vorwerk, J. Magee, and S.B. Carroll. 1996. Integration of positional signals and regulation of wing formation and identity by Drosophila vestigial gene. Nature 382: 133-138.

Jackson, P.D. and F.M. Hoffmann. 1994. Embryonic expression patterns of the Drosophila decapentaplegic gene: Separate regulatory elements control blastoderm expression and lateral ectodermal expression. Dev. Dynam. 199: 28-44.

Jügens, G., E. Wieschaus, C. Nüsslein-Volhard, and H. Kluding. 1984. Mutations affecting the pattern of the larval cuticle in Drosophila melanogaster: II. Zygotic loci on the third chromosome. Wilhelm Roux's Arch. Dev. Biol. 193: 283-295.

Lawrence, P. and G. Struhl. 1996. Morphogens, compartments, and pattern: Lessons from Drosophila? Cell 85: 951-961.

Lee, W., P. Mitchell, and R. Tjian. 1987. Purified transcription factor AP-1 interacts with TPA-inducible enhancer elements. Cell 49: 741-752.

Letsou, A., K. Arora, J.L. Wrana, K. Simin, V. Twombly, J. Jamal, K. Staehling-Hampton, M.F. Hoffmann, W.M. Gelbert, J. Massagué, and M.B. O'Connor. 1995. Drosophila dpp signaling is mediated by the punt gene product: A dual ligandbinding type II receptor of the TGF $\beta$ receptor family. Cell 80: 899-908.

Lindsley, D. and G. Zimm. 1990. The genome of Drosophila melanogaster, 4. Genes L-Z, balancers, transposable elements. Dros. Inf. Serv. 68.

Lu, X., M.B. Melnick, J.C. Hsu, and N. Perrimon. 1994. Genetic and molecular analyses of mutations involved in Drosophila raf signal transduction. EMBO J. 13: 2592-2599.

Luo, L., Y.J. Liao, L.Y. Jan, and Y.N. Jan. 1994. Distinct morphogenetic functions of similar small GTPases: Drosophila Drac1 is involved in axonal outgrowth and myoblast fusion. Genes \& Dev. 8: 1787-1802.

Mackrell, A.J., B. Blumberg, S.R. Haynes, and J.H. Fessler. 1988. The lethal myospheroid gene of Drosophila encodes a membrane protein homologous to vertebrate integrin b subunits. Proc. Natl. Acad. Sci. 85: 2633-2637.

Martinez Arias, A. 1993. Development and patterning of the larval epidermis of Drosophila. In The development of Drosophila melanogaster (ed. M. Bate and A. Martinez Arias), pp. 517-608. Cold Spring Harbor Laboratory Press, Cold Spring Harbor, NY.

Minden, A., A. Lin, F.-X. Claret, A. Abo, and M. Karin. 1995. Selective activation of the JNK signaling casacade and c-Jun transcriptional activity by the small GTPases Rac and Cdc42Hs. Cell 81: 1147-1157.

Nellen, D., M. Affolter, and K. Basler. 1994. Receptor serine/ threonine kinases implicated in the control of Drosophila body pattern by decapentaplegic. Cell 78: 225-237.

Nüsslein-Volhard, C., E. Wieschaus, and H. Kluding. 1984. Mutations affecting the pattern of the larval cuticle in Drosophila melanogaster: I. Zygotic loci on the second chromosome. Wilhelm Roux's Arch. Dev. Biol. 193: 267-282.

Penton, A., Y. Chen, K. Staehling-Hampton, J.L. Wrana, L. Attisano, J. Szidonya, J.A. Cassill, J. Massagué, and M.F. Hoffmann. 1994. Identification of two bone morphogenetic pro- 
tein type I receptors in Drosophila and evidence that Brk25D is a decapentaplegic receptor. Cell 78: 239-250.

Perkins, K.K., A. Admon, N. Patel, and R. Tjian. 1990. The Drosophila fos-related AP-1 protein is a developmentally regulated transcription factor. Genes \& Dev. 4: 822-834.

Perrimon, N., L. Engstrom, and A.P. Mahowald. 1989. Zygotic lethals with specific maternal effect phenotypes in Drosophila melanogaster. I. Loci on X chromosome. Genetics 121: 333-352.

Peverali, F.A., A. Isaksson, A.G. Papavassiliou, P. Plastina, L.M. Staszewski, M. Mlodzik, and D. Bohmann. 1996. Phosphorylation of Drosophila Jun by the MAP kinase Rolled regulates photoreceptor differentiation. EMBO I. 15: 3943-3950.

Ray, R.P., K. Arora, C. Nüsslein-Volhard, and W.M. Gelbert. 1991. The control of cell fate along the dorsal-ventral axis of the Drosophila embryo. Development 113: 35-54.

Ray, R.P. and T. Schupbach. 1996. Intercellular signaling and the polarization of body axes during Drosophila oogenesis. Genes \& Dev. 10: 1711-1723.

Riesgo-Escovar, J.R., M. Jenni, A. Fritz, and E. Hafen. 1996. The Drosophila Jun-N-terminal kinase is required for cell morphogenesis but not for DJUN-dependent cell fate specification in the eye. Genes \& Dev. 10: 2759-2768.

Ruberte, E., T. Marty, D. Nellen, M. Affolter, and K. Basler. 1995. An absolute requirement for both the type II and type I receptors, punt and thick veins, for dpp signaling in vivo. Cell 80: 890-898.

Rusch, J. and M. Levine. 1997. Regulation of a dpp target gene in the Drosophila embryo. Development 124: 303-311.

Ryder, K., L.F. Lau, and D. Nathans. 1989. A gene activated by growth factors is related to oncogene v-jun. Proc. Natl. Acad. Sci. 85: 1487-1491.

Sambrook, J., E.F. Fritsch, and T. Maniatis. 1989. Molecular cloning: A laboratory manual. Cold Spring Harbor Laboratory Press, Cold Spring Harbor, NY.

Sluss, H.K., Z. Han, T. Barrett, R.J. Davis, and T.Y. Ip. 1996. A INK signal transduction pathway that mediates morphogenesis and an immune response in Drosophila. Genes \& Dev. 10: $2745-2758$.

Spradling, A.C. and G.M. Rubin. 1982. Transposition of cloned P-elements into Drosophila germ line chromosomes. Science 218: $341-347$.

St. Johnston, R.D. and W.M. Gelbert. 1987. decapentaplegic transcripts are localized along the dorsal-ventral axis of the Drosophila embryo. EMBO T. 6: 2785-2791.

Staehling-Hampton, K., A.S. Laughon, and M.F. Hoffmann. 1995. A Drosophila protein related to the human zinc finger transcription factor PRDII/MBP/HIV-EP1 is required for dpp signaling. Development 121: 3393-3403.

Treier, M., D. Bohmann, and M. Mlodzik. 1995. Jun cooperates with the ETS domain protein Pointed to induce photoreceptor R7 fate in the Drosophila eye. Cell 83: 753-760.

Wang, G.L. and E.S. Goldstein. 1994. Transcription of Diun from $D$. melanogaster is positively regulated by DTF-1, AP1, and CREB binding sites. Exp. Cell Res. 214: 389-399.

Wieschaus, E., C. Nüsslein-Volhard, and G. Jürgens. 1984. Mutations affecting the pattern of the larval cuticle in Drosophila melanogaster: III. Zygotic loci on the X-chromosome. Wilhelm Roux's Arch. Dev. Biol. 193: 296-307.

Wilcox, M., A. DiAntonio, and M. Leptin. 1989. The function of PS integrins in Drosophila wing morphogenesis. Development 107: 891-897.

$\mathrm{Xu}, \mathrm{T}$. and G.M. Rubin. 1993. Analysis of genetic mosaics in developing and adult Drosophila tissues. Development 117: 1223-1237.

Young, P.E., A.M. Richman, A.S. Ketchum, and D.P. Kiehart.
1993. Morphogenesis in Drosophila requires nonmuscle myosin heavy chain function. Genes \& Dev. 7: 29-41.

Zhang, K., R. Chaillet, L.A. Perkins, T.D. Halazonetis, and N. Perrimon. 1990. Drosophila homolog of the mammalian jun oncogene is expressed during embryonic development and activates transcription in mammalian cells. Proc. Natl. Acad. Sci. 87: 6281-6285. 


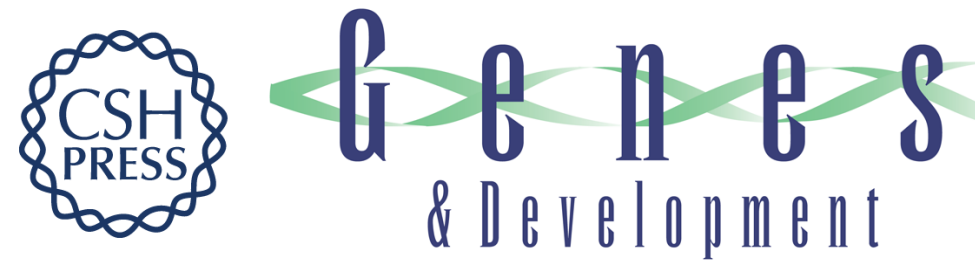

\section{Drosophila Jun relays the Jun amino-terminal kinase signal transduction pathway to the Decapentaplegic signal transduction pathway in regulating epithelial cell sheet movement.}

X S Hou, E S Goldstein and N Perrimon

Genes Dev. 1997, 11:

Access the most recent version at doi:10.1101/gad.11.13.1728

References This article cites 60 articles, 25 of which can be accessed free at:

http://genesdev.cshlp.org/content/11/13/1728.full.html\#ref-list-1

License

Email Alerting Service

Receive free email alerts when new articles cite this article - sign up in the box at the top right corner of the article or click here.

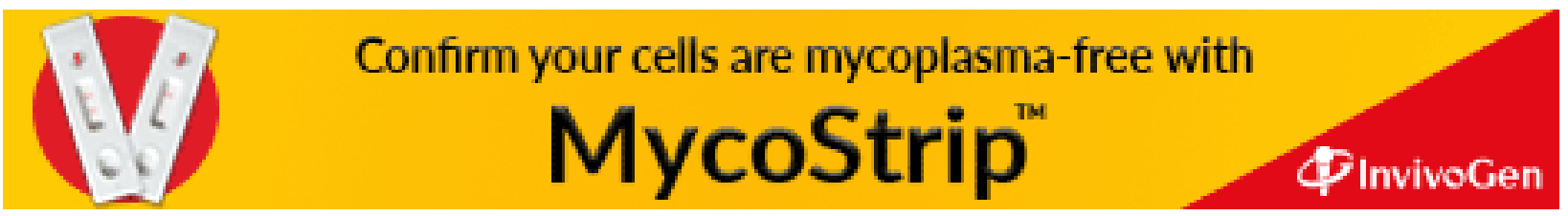

